\title{
Respon Varietas Tebu Unggul Baru Terhadap Pemberian Nano Silika dan Cekaman Kekeringan
}

\section{Response of New Superior Cane Varieties to The Nano Silica Application and Water Stress}

\author{
Vega Kartika Sari ${ }^{1 *}$, Kacung Haryono ${ }^{1}$, dan Basuki Basuki ${ }^{1}$ \\ ${ }^{1}$ Fakultas Pertanian, Universitas Jember Jl. Kalimantan No. 37, Jember, Jawa Timur \\ *E-mail : vegakartikas@unej.ac.id
}

\begin{abstract}
The development pattern of sugarcane on the island of Java has shifted to dry land because rice fields are prioritized for other food crops. Dryland generally has low to moderate fertility rates and water availability is a limiting factor. Silicate (Si) is a beneficial nutrient for sugarcane and is absorbed in greater quantities than other nutrients. Si also can avoid damage to plants against abiotic stress such as drought. This study aims to test several new highyielding sugarcane varieties under drought conditions and their responses to Si fertilization. The design used was three-factor RAK, namely the concentration of nano-silica fertilizer $(0 \%$; $30 \%$; 45\%), watering intensity (regular watering; no watering from 45 DAS), and new high yielding sugarcane varieties (BL; NX 01; NX 02; NX 03; VMC 86-550). The observation variables included stover fresh weight, root fresh weight, root length, and stover dry weight. The data obtained were analyzed by ANOVA at a 95\% confidence level. If it is significantly different, continue with the $5 \%$ LSD test. Based on the results of this study, it was shown that the new superior sugarcane variety, namely VMC 86-550, was drought tolerant, indicated by the best average growth in almost all observed parameters. The concentration of nano-silica fertilizer $45 \%$ for 2 times the application showed the best growth of sugarcane. The treatment interaction between drought and variety had a significant effect on the wet weight of stover and root length of sugarcane. Treatment of nano-silica had a significant effect on the dry weight of sugarcane stover.
\end{abstract}

Keywords: water stress, nano-silica, sugarcane

Disubmit : 02 Maret 2021, Diterima: 05 Juli 2021, Disetujui : 04 Agustus 2021

\section{PENDAHULUAN}

Tebu (Saccharum officinarum L.) merupakan salah satu anggota famili Graminae yang tumbuh di daerah tropika dan sub tropika (Sari dan Indrawati, 2019). Tanaman perkebunan/industri ini memiliki peran penting, karena digunakan sebagai bahan baku utama pembuatan gula. Sekitar 65\% produksi gula di dunia berasal dari bahan baku tebu (Basuki et al., 2015). Kebutuhan akan tanaman ini terus meningkat seiring meningkatnya pertambahan penduduk di Indonesia terutama meningkatnya konsumsi gula Nasional, namun produksi yang dihasilkan belum dapat mengimbanginya (Sari dan Hariyono, 2020). Menurut Basuki dan Sari (2019), penurunan produksi tebu di Jawa Timur disebabkan oleh penggunaan varietas tebu yang tidak sesuai dengan jenis tanah dan iklim, eksploitasi lahan dan penggunaan pupuk yang tidak seimbang, yang menyebabkan kondisi biologi, dan kimia dalam tanah berubah. Hunsigi (2001) menambahkan, sistem tanam monokultur terus-menerus akan mengurangi hara tersedia dalam tanah, apabila penambahan unsur hara dalam 
tanah tidak sesuai dan tidak rasional. Pemupukan merupakan salah satu faktor strategis yang berpengaruh langsung terhadap produktifitas dan nilai ekonomi.

Penurunan produktivitas tebu dapat disebabkan oleh penurunan kandungan silika $(\mathrm{Si})$ tersedia dalam tanah. Tanaman tebu mengakumulasi Si dan disimpan dalam jaringan tanaman seperti batang dan daun. Unsur silika merupakan unsur fungsional bagi tanaman tebu, berperan dalam pembentukan, penyimpanan, dan mempertahankan kandungan sukrosa dalam tebu. Pemberian pupuk Si ke dalam tanah dapat berupa serbuk, butiran, maupun larutan. Unsur Si diserap dalam bentuk asam silikat yang tingkat serapannya tergantung konsentrasinya di dalam larutan tanah (Djajadi et al., 2016). Menurut Yukamgo \& Yuwono (2007), secara umum tanah pertanian Indonesia memiliki tingkat ketersediaan $\mathrm{Si}$ yang rendah. Silika tersedia (asam monosilikat) merupakan unsur yang mudah larut. Kehilangan Si pada tanah Indonesia terjadi akibat terbawa aliran air drainase atau tanaman setelah mineral tanah melepas $\mathrm{Si}$, sehingga perlu upaya pemupukan Si untuk tanah yang kekurangan unsur Si. Pikukuh et al. (2015) dan Syahri et al. (2016) menggunakan pupuk nano Si dalam penelitiannya pada tanaman tebu melalui aplikasi penyemprotan pupuk sebanyak 4 kali dengan konsentrasi $30 \%$ pada tebu berpengaruh positif terhadap pertumbuhan tanaman tebu. Mohseni \& Sabbagh (2014) menambahkan, Si yang ditambahkan pada media tanam dapat menghindari kerusakan tanaman terhadap cekaman abiotik seperti salinitas dan kekeringan.

Pemahaman tentang kebutuhan air dalam budidaya tebu sangat penting dalam upaya mendukung swasembada tebu. Menurut Ramadhan et al. (2014), dalam dua dasawarsa terakhir, penanaman tebu bergeser dari lahan sawah ke lahan tegalan (kering). Hal tersebut disebabkan, lahan berpengairan diutamakan untuk tanaman pangan. Konsekuensi yang timbul ialah pada aspek produktivitas tebu. Keragaman hasil tebu di lahan kering rata-rata masih lebih rendah dibanding tebu di lahan sawah. Mastur (2016) menambahkan, pengembangan areal tebu baru mengarah kepada daerah-daerah yang memiliki curah hujan relatif rendah seperti di Blora, Rembang, Bojonegoro, Tuban, Lamongan, Dompu, dan Pulau Madura yang rentan terhadap ancaman kekeringan . Kekeringan juga dapat terjadi karena perubahan iklim, seperti adanya El Nino yang terjadi pada tahun 2015 yang mengakibatkan penurunan total produksi gula.

Budidaya tebu di lahan kering harus memperhatikan klon tebu yang sesuai. Penggunaan varietas unggul baru tebu yang tahan terhadap cekaman lingkungan terutama kekeringan merupakan langkah yang sesuai dan diharapkan dapat memberikan kontribusi dalam pengembangan tebu di wilayah yang mempunyai agroekosistem spesifik. Hasil penelitian Santoso et al.(2015) menunjukkan bahwa dari enam varietas tebu yang digunakan daya adaptasi terhadap kekeringan beragam antar varietas. Demikian pula hasil penelitian Zao et al.(2013), respon genotipe berbeda nyata dan konsisten menurunkan panjang batang, jumlah buku dan anakan pada kondisi kekeringan. Penelitian ini bertujuan untuk mengetahui pengaruh nano silika pada lima varietas unggul baru terhadap cekaman kekeringan.

\section{METODE PENELITIAN}

Penelitian ini dilaksanakan pada bulan Agustus sampai dengan November 2020 di Greenhouse yang berlokasi di Kecamatan Tegalampel, Kabupaten Bondowoso. Bahan penelitian yang digunakan meliputi bibit varietas tebu BL, NX 01, NX 02, NX 03, dan VMC 86-550 bagal mata satu yang diperoleh dari Pusat Penelitian Jengkol PTPN X Kediri, nano Silika dalam bentuk powder, tanah entisol sebagai media tanam, polybag, pupuk NPK, dan bahan kemikalia analisis parameter tanah. Alat yang digunakan dalam penelitian meliputi penggaris, jangka sorong, timbangan, gelas ukur, label, oven dan alat laboratorium untuk analisis parameter tanah.

Penelitian ini menggunakan metode Rancangan Acak Kelompok (RAK) Faktorial yang terdiri atas 3 faktor. Faktor pertama yaitu konsentrasi pupuk nano silika (S) terbagi atas 3 konsentrasi $(0 \%, 30 \%$, dan $45 \%)$ dengan aplikasi silika dilakukan sebanyak 2 kali yaitu pada 14 HST dan 35 HST. Faktor kedua yaitu varietas tanaman tebu (V) yang terdiri dari BL, NX 01, NX 02, NX 03, dan VMC 86-550. Faktor ketiga yaitu cekaman air/ kekeringan $(\mathrm{P})$ dengan 2 perlakuan penyiraman terdiri atas penyiraman intensif dan tanpa penyiraman dimulai pada 45HST. 
Untuk mendukung penelitian, variabel pengamatan yang digunakan meliputi bobot brangkasan basah, bobot brangkasan kering, bobot akar, dan panjang akar. Data hasil pengamatan dianalisis dengan Analysis of Variance (ANOVA) pada tingkat kepercayaan 95\%, dan apabila berpengaruh nyata dilanjutkan dengan Uji BNT taraf $5 \%$.

\section{HASIL DAN PEMBAHASAN}

Jenis tanah yang digunakan pada penelitian ini ialah tanah entisol yang memiliki parameter karakteristik kimia tanah dengan nilai harkat yang rendah. Peningkatan kualitas tanah melalui aplikasi pupuk nano silika pada tanah entisol dilakukan dengan tujuan meningkatkan ketersediaan unsur hara untuk mendukung pertumbuhan tanaman tebu diukur melalui parameter Nitrogen Total Tanah, $\mathrm{P}_{2} \mathrm{O}_{5}$ tersedia, $\mathrm{K}_{2} \mathrm{O}$ tersedia, $\mathrm{Si}$ tersedia yang disajikan pada Tabel 1. Pemberian pupuk nano silika dengan dosis $30 \%$, dan $45 \%$ mampu meningkatkan unsur hara makro primer tanah dibandingkan dengan perlakuan tanpa pemberian silika. Aplikasi pupuk nano silika 45\% mampu meningkatkan nitrogen total tanah sebesar 47\%. Unsur hara makro primer lain seperti Pospat tersedia $\left(\mathrm{P}_{2} \mathrm{O}_{5}\right)$, $\mathrm{K}$ tersedia $\left(\mathrm{K}_{2} \mathrm{O}\right)$, dan $\mathrm{Si}$ tersedia dengan aplikasi nano silika $45 \%$ juga meningkat. Adapun peningkatan $\mathrm{P}_{2} \mathrm{O}_{5}, \mathrm{~K}_{2} \mathrm{O}$, Si tersedia secara berturut-turut yaitu 39,13\%; 15,15\%; dan $62,90 \%$. Hal tersebut sesuai dengan yang dinyatakan oleh Pikukuh et al., (2015) bahwa peran Si pada tanaman tebu, antara lain meningkatkan unsur hara makro seperti P tersedia tanah.

Tabel 1. Hasil analisis parameter kimia tanah setelah aplikasi nano silika

\begin{tabular}{lcccc}
\hline \multirow{2}{*}{ Parameter } & \multicolumn{3}{c}{ Dosis Pupuk Silika } & \multirow{2}{*}{ Metode spesifikasi } \\
\cline { 2 - 4 } & Si 0\% & Si 30\% & Si 45\% & Kjeldahl (SNI 19-7030-2004) \\
N Total (\%) & 0,048 & 0,110 & 0,112 & SNI 2803:2010 \\
$\mathrm{P}_{2} \mathrm{O}_{5}$ Tersedia (\%) & 0,014 & 0,015 & 0,023 & SNI 2803:2010 \\
$\mathrm{K}_{2} \mathrm{O}$ Tersedia (\%) & 0,028 & 0,031 & 0,033 & SNI 2803:2010 \\
Silika Tersedia (\%) & 0,023 & 0,047 & 0,062 & \\
\hline
\end{tabular}

Hasil analisis ragam pengaruh aplikasi pupuk nano silika, perlakuan kekeringan, dan jenis varietas terhadap empat parameter pengamatan disajikan pada Tabel 2. Hasil analisis menunjukkan bahwa perlakuan pupuk nano silika berpengaruh nyata dalam meningkatkan bobot kering brangkasan. Silika dalam tanaman tebu mampu meningkatkan ketebalan kulit batang tebu yang berpengaruh pada peningkatan bobot (Pawirosemadi, 2011). Perlakuan kekeringan berpengaruh terhadap bobot basah brangkasan, bobot akar, dan bobot kering brangkasan. Air merupakan bagian penyusun dalam proses fotosintesis dalam pembentukan karbohidrat sehingga pemberian air yang cukup dapat meningkatkan kuantitas tanaman tebu (Basuki, 2020). Perlakuan varietas berdasarkan analisis sidik ragam berpengaruh nyata dalam meningkatkan bobot akar, panjang akar, dan bobot kering brangkasan. Varietas tanaman tebu terbagi atas masak awal, tengah, dan lambat yang masing-masing memiliki karakteristik morfologi dan fisiologi yang dibentuk oleh genetik sehingga masing-masing varietas akan menunjukkan performa terhadap lingkungan yang berbeda baik secara kualitatif maupun kuantitatif (Utami et al., 2019). Interaksi antara perlakuan kekeringan dan jenis varietas tanaman tebu berpengaruh nyata terhadap bobot basah brangkasan dan panjang akar. Varietas tebu yang sesuai dengan karakteristik lingkungan tumbuh yang sesuai akan meningkatkan produktifitas (Basuki, 2020).

Tabel 2. Rekapitulasi hasil analisis ragam pengaruh berbagai konsentrasi nano silika, perlakuan kekeringan, dan varietas pada beberapa parameter pengamatan tanaman tebu

\begin{tabular}{lccccccc}
\hline \multicolumn{1}{c}{ Variabel Pengamatan } & Silika $(\mathrm{S})$ & Kekeringan $(\mathrm{P})$ & Varietas $(\mathrm{V})$ & $\mathrm{S} * \mathrm{P}$ & $\mathrm{S} * \mathrm{~V}$ & $\mathrm{P} * \mathrm{~V}$ & $\mathrm{~S} * \mathrm{P} * \mathrm{~V}$ \\
\hline Bobot Basah Brangkasan & tn & $*$ & tn & tn & tn & $*$ & tn \\
Bobot Akar & tn & $*$ & $*$ & tn & tn & tn & tn \\
Panjang Akar & tn & tn & $*$ & tn & tn & $*$ & tn \\
Bobot Kering brangkasan & $*$ & $*$ & $*$ & tn & tn & tn & tn \\
\hline
\end{tabular}

Keterangan: $*$ = berpengaruh nyata pada taraf $5 \% ; \mathrm{tn}=$ berpengaruh tidak nyata pada taraf $5 \%$ 
Menurut Sujinah dan Jamil (2016), pertumbuhan tanaman terjadi karena proses pembelahan, pembesaran, dan diferensiasi sel yang melibatkan unsur genetik, fisiologi, ekologi, dan morfologi serta interaksinya. Tebu merupakan tanaman $\mathrm{C} 4$ yang memiliki kemampuan memanfaatkan radiasi matahari dalam laju fotosintesis yang tinggi, namun memerlukan kecukupan air sesuai dengan fase pertumbuhan (Mastur, 2016). Kualitas dan kuantitas pertumbuhan tanaman tebu bergantung pada unsur hara dan dipengaruhi oleh ketersediaan air. Berdasarkan fase pertumbuhan tanaman tebu, kebutuhan air tertinggi di serap pada fase perpanjangan dengan absobsi sebesar $8,00 \mathrm{~mm} /$ hari, diikuti fase anakan sebesar 7,33 $\mathrm{mm} / \mathrm{hari}$, fase perkecambahan sebesar 6,67 mm/hari, dan fase pemasakan sebesar 5,00 mm/hari (Prasanna \& Pattar, 2014). Proses kekeringan diberlakuakan pada umur 45 HST yang merupakan fase dimana kebutuhan air tinggi. Pengeringan mampu mempengaruhi proses fisiologis tanaman tebu. Hal tersebut sejalan dengan yang diungkapkan Allah et al. (2010), kekurangan air mengakibatkan proses fisiologis maupun morfologis tidak normal, yang menyebabkan pertumbuhan tanaman terhambat atau terhenti. Respon tanaman terhadap kekeringan dalam jangka panjang ialah menurunnya jumlah dan luas daun serta batang, serta perubahan biokimia (Mastur, 2016).

Tabel 3. Nilai tengah pengaruh tiap perlakuan terhadap parameter pengamatan

\begin{tabular}{lllll}
\hline Perlakuan & $\begin{array}{l}\text { Bobot Brangkasan } \\
\text { Basah }(\mathrm{g})\end{array}$ & $\begin{array}{l}\text { Bobot Akar } \\
(\mathrm{g})\end{array}$ & $\begin{array}{l}\text { Panjang Akar } \\
(\mathrm{cm})\end{array}$ & $\begin{array}{l}\text { Bobot Kering } \\
\text { brangkasan }(\mathrm{g})\end{array}$ \\
\hline Silika dosis 0\% (S1) & $203,23 \mathrm{a}$ & $54,20 \mathrm{a}$ & $68,86 \mathrm{a}$ & $29,34 \mathrm{a}$ \\
Silika dosis 30\% (S2) & $240,13 \mathrm{a}$ & $50,30 \mathrm{a}$ & $67,63 \mathrm{a}$ & $30,93 \mathrm{a}$ \\
Silika dosis 45\% (S3) & $278,37 \mathrm{a}$ & $65,72 \mathrm{a}$ & $76,41 \mathrm{a}$ & $41,36 \mathrm{~b}$ \\
\hline Tanpa kekeringan (P1) & $327,47 \mathrm{~b}$ & $73,48 \mathrm{~b}$ & $70,68 \mathrm{a}$ & $44,46 \mathrm{~b}$ \\
Kekeringan (P2) & $150,86 \mathrm{a}$ & $39,90 \mathrm{a}$ & $71,13 \mathrm{a}$ & $23,91 \mathrm{a}$ \\
\hline BL (V1) & $69,55 \mathrm{a}$ & $59,70 \mathrm{ab}$ & $69,64 \mathrm{ab}$ & $30,62 \mathrm{ab}$ \\
NX 01 (V2) & $73,05 \mathrm{a}$ & $37,38 \mathrm{a}$ & $73,13 \mathrm{ab}$ & $27,86 \mathrm{a}$ \\
NX 02 (V3) & $78,50 \mathrm{a}$ & $66,44 \mathrm{bc}$ & $78,52 \mathrm{~b}$ & $41,77 \mathrm{~b}$ \\
NX 03 (V4) & $56,77 \mathrm{a}$ & $37,10 \mathrm{a}$ & $56,81 \mathrm{a}$ & $30,44 \mathrm{ab}$ \\
VMC 86-550 (V5) & $77,05 \mathrm{a}$ & $82,83 \mathrm{c}$ & $77,11 \mathrm{~b}$ & $34,18 \mathrm{~b}$ \\
\hline
\end{tabular}

Keterangan: angka yang diikuti huruf yang sama pada kolom yang sama tidak berbeda nyata

Bobot Basah Brangkasan. Perlakuan daya tahan pengeringan $(\mathrm{P} 2=150,86 \mathrm{~g})$ yang dilakukan mulai umur 45 hari sampai 75 hari setelah tanah menunjukkan perbedaan yang nyata terhadap perlakuan tanpa pengeringan $(\mathrm{P} 1=327,47 \mathrm{~g})$ dengan selisih bobot turun 176,61 gram $(53,93 \%)$ (Tabel 3). Hasil uji lanjutan nilai tengah interaksi antar perlakuan kekeringan dan varietas terhadap bobot basah brangkasan (Tabel 4) menunjukkan bahwa interaksi yang erat dengan nilai > 0,7 yang ditunjukkan dengan varietas yang mampu bertahan pada kondisi kering, dan menunjukkan performa yang baik terhadap berat brangkasan basah yaitu Varietas NX 01 (V2) dengan nilai bobot sebesar 235,11 gram.

Tabel 4. Pembandingan berganda interaksi varietas dan kekeringan terhadap bobot basah brangkasan

\begin{tabular}{lcc}
\hline V (Varietas) & P1 (Tanpa Kekeringan) & P2 (Kekeringan) \\
\hline BL (V1) & $381,67 \mathrm{~A}$ & $131,94 \mathrm{~A}$ \\
NX 01 (V2) & $\mathrm{a}$ & $\mathrm{b}$ \\
& $221,22 \mathrm{~B}$ & $235,11 \mathrm{~A}$ \\
NX 02 (V3) & $\mathrm{a}$ & $\mathrm{a}$ \\
& $395,33 \mathrm{~A}$ & $152,17 \mathrm{~A}$ \\
NX 03 (V4) & $\mathrm{a}$ & $\mathrm{b}$ \\
& $283,78 \mathrm{AB}$ & $100,56 \mathrm{~A}$ \\
VMC 86-550 (V5) & $\mathrm{a}$ & $\mathrm{b}$ \\
& $355,33 \mathrm{~A}$ & $182,67 \mathrm{~A}$
\end{tabular}

Keterangan: angka yang diikuti huruf kecil yang sama pada baris yang sama dan huruf kapital pada kolom yang sama tidak berbeda nyata 
Bobot Akar. Hasil uji lanjut nilai tengah perlakuan terhadap bobot akar tanaman tebu umur 14 MST (Tabel 3), menunjukkan bahwa perlakuan S3 memberikan bobot akar lebih besar $(65,72 \mathrm{~g})$ meskipun tidak berbeda nyata dengan perlakuan silika lainnya. Perlakuan tanpa kekeringan memberikan bobot akar yang lebih besar $(73,5 \mathrm{~g})$ dan berbeda nyata dengan perlakuan kekeringan $(39,9 \mathrm{~g})$. Varietas VMC 86-550 (V5) menghasilkan bobot akar yang lebih besar daripada varietas lainnya.

Panjang Akar. Berdasarkan Tabel 3 menunjukkan bahwa pada perlakuan S3 menghasilkan rata-rata panjang akar yang lebih besar daripada perlakuan Si lainnya. Panjang akar pada perlakuan P2 menunjukkan rata-rata panjang akar yang lebih besar. Varietas VMC 86-550 (V5) memiliki akar yang lebih panjang daripada varietas lainnya. Pada parameter panjang akar meskipun perlakuan kekeringan tidak berpengaruh nyata, namun secara nilai rata-rata panjang akar lebih besar. Menurut Mastur (2016), respon cepat tanaman terhadap kekeringan adalah penutupan stomata, selanjutnya dalam jangka panjang terjadi perubahan pertumbuhan dengan meningkatnya pertumbuhan akar. Allah et al., (2010) menambahkan, mekanisme ketahanan tanaman terhadap kekeringan antara lain dengan memanjangkan akarnya untuk mencari sumber air pada saat terjadi cekaman kekeringan.

Tabel 5. disajikan hasil analisis interaksi varietas dengan kekeringan. Interaksi antara kelima varietas dengan tanpa kekeringan menunjukkan Varietas NX 02 memiliki panjang akar yang paling besar $(82,3 \mathrm{~cm})$, sedangkan Varietas VMC 86-550 memiliki panjang akar paling besar pada kondisi kekeringan $(76,9 \mathrm{~cm})$. VMC 86-550 juga memiliki kondisi panjang akar yang tidak berbeda nyata dengan selisih penurunan paling kecil dibandingkan varietas lainnya. Hal tersebut menunjukkan VMC 86-550 mampu beradaptasi baik pada kondisi kekeringan maupun tanpa kekeringan.

Tabel 5. Pembandingan berganda interaksi varietas dan kekeringan terhadap panjang akar

\begin{tabular}{lcc}
\hline Varietas (V) & P1 & P2 \\
& (Tanpa Kekeringan) & (Kekeringan) \\
\hline BL (V1) & $75,6 \mathrm{~A}$ & $\mathrm{a}$ \\
NX 01 (V2) & $\mathrm{a}$ & $76,1 \mathrm{~A}$ \\
NX 02 (V3) & $70,0 \mathrm{~A}$ & $\mathrm{a}$ \\
& $\mathrm{a}$ & $74,7 \mathrm{~A}$ \\
NX 03 (V4) & $82,3 \mathrm{~A}$ & $\mathrm{a}$ \\
& $\mathrm{a}$ & $65,2 \mathrm{~A}$ \\
VMC 86-550 (V5) & $48,3 \mathrm{~B}$ & $\mathrm{a}$ \\
& $\mathrm{a}$ & $76,9 \mathrm{~A}$ \\
& $77,2 \mathrm{~A}$ & $\mathrm{a}$ \\
\hline
\end{tabular}

Keterangan: angka yang diikuti huruf kecil yang sama pada baris yang sama dan huruf kapital pada kolom yang sama tidak berbeda nyata

Bobot Kering Brangkasan. Berdasarkan Tabel 3, pada perlakuan S3 menghasilkan rata-rata bobot kering brangkasan yang lebih besar daripada perlakuan Si lainnya. Hasil penelitian menunjukkan bahwa pemupukan Si berpengaruh terhadap bobot tanaman tebu, yang meningkat sebesar 9-12\% dibandingkan tanpa pemupukan Si (Mulyadi dan Toharisman, 2003). Terdapat perbedaan nyata pengaruh kekeringan dan tanpa kekeringan terhadap bobot kering tanaman. Varietas VMC 86-550 (V5) termasuk varietas yang menghasilkan bobot kering brangkasan terbesar. Berdasarkan hal tersebut dapat diduga bahwa VMC 86-550 termasuk genotipe toleran kekeringan. Hasil penelitian Medeiros et al. (2013) menunjukkan bahwa bobot kering bagian atas pada genotipe peka menurun nyata, demikian pula bobot kering akar, dan biomas total, namun pada genotipe toleran kekeringan tidak berpengaruh nyata.

Setelah aplikasi kekeringan, nano silika tidak berpengaruh nyata hampir seluruh parameter pengamatan kecuali bobot kering brangkasan. Namun demikian, pemberian nano silika konsentrasi $45 \%$ sebanyak 2 kali aplikasi menunjukkan pertumbuhan tanaman yang lebih baik. Hal tersebut menunjukkan pemberian nano silika membantu meminimalkan kerusakan jaringan akibat cekaman abiotik/kekeringan. 
Menurut Mohseni \& Sabbagh (2014), Si yang ditambahkan pada media tanam dapat menghindari kerusakan tanaman terhadap cekaman abiotik seperti salinitas dan kekeringan.

Faktor varietas berpengaruh nyata hampir pada seluruh parameter pengamatan. Berdasarkan hasil uji lanjut menunjukkan bahwa dari lima varietas yang diuji menunjukkan respon berbeda nyata. Mastur (2016) menyimpulkan dari hasil penelitian berbagai sumber bahwa genotipe berbeda memberikan respon berbeda terhadap kekeringan. Lebih lanjut dipaparkan, stress air pada varietas-varietas tebu komersial menyebkan penurunan yang nyata pada total bahan kering, dan produktivitas, namun pada genotipe non-komersial penurunan total bahan kering dan produktivitas lebih kecil. Genotipe relative toleran kekeringan mengalami penurunan berat batang/plot tidak nyata (hanya berkisar 3\%-5\%), sedangkan genotipe yang peka kekeringan mengalami penurunan 50\%-60\%.

Berdasarkan hasil sidik ragam untuk faktor tunggal varietas, VMC86-550 (V5) menunjukkan pertumbuhan tanaman yang lebih baik hampir pada seluruh parameter pertumbuhan, dan berdasarkan pengaruh interaksinya dengan kekeringan menghasilkan bobot basah brangkasan dan panjang akar yang paling besar dan tidak berbeda berbeda nyata dibandingkan pada kondisi tanpa kekeringan. Dapat dikatakan bahwa varietas tersebut lebih toleran terhadap kekeringan daripada varietas lainnya yang diuji. Sejalan dengan hasil penelitian Ramadhan et al., (2014), dari lima klon yang diuji, VMC 86-550 diketahui cocok dibudidayakan di tanah lahan kering jenis Inceptisol berdasarkan pengamatan rendemen. Menurut Ismadi (2016), VMC 86-550 merupakan salah satu varietas andalan PTPN XI karena karakternya yang menonjol yaitu walaupun tergolong varietas dengan tipe kemasakan awal namun mempunyai rentang daya tahan yang lebih panjang dibandingkan jenis masak awal lainnya. Potensi cukup tinggi dapat mencapai \pm 1500 kui/ha untuk plant cane (PC) dan \pm 1100 kui/ha untuk ratoon 1 , rendemen $\pm 9,55 \%$. Lebih lanjut Ismadi (2016) mengungkapkan bahwa varietas ini cocok dikembangkan baik di tegalan ataupun sawah dengan pengairan yang cukup. VMC 86-550 yang merupakan varietas introduksi dari Philipina, memiliki kepanjangan Victoria Milling Company yang serupa dengan P3GI. Varietas ini merupakan keturunan dari indukan polycross PS 6226. Sifat khas dari varietas ini ialah mudah klenthek, batang diameter sedang-besar, tegak, berbunga sporadik dan kadar sabut 11-12\%.

\section{KESIMPULAN}

Interaksi perlakuan nano silika dengan perlakuan kekeringan pada semua parameter pertumbuhan tanaman tebu pada fase pembibitan, kecuali interaksi kekeringan dan varietas yang menunjukkan pengaruh berbeda nyata untuk parameter bobot basah brangkasan dan panjang akar tanaman tebu. Faktor tunggal nano silika berpengaruh nyata pada bobot kering brangkasan tebu. Pemberian nano silika konsentrasi $45 \%$ sebanyak 2 kali memberikan respon yang lebih baik hampir pada seluruh parameter pertumbuhan. Perlakuan kekeringan mulai 45 HST selama 30 hari berpengaruh nyata pada diameter batang, bobot akar, bobot basah brangkasan dan bobot kering brangkasan. Varietas VMC 86-550 menunjukkan toleransi terhadap kekeringan dibandingkan varietas lainnya yang diuji.

\section{DAFTAR PUSTAKA}

Allah, A. A. A., Ammar, M. H., \& Badawi, A. T. 2010. Screening rice genotypes for drought resistance in Egypt. Journal of plant breeding and crop science, 2(7), 205-215. http://www.academicjournals.org/jpbcs

Basuki, Purwanto, B.H., Sunarminto, B.H., \& Utami, S.N.H. 2015. Analisis cluster sebaran hara makro dan rekomendasi pemupukan untuk tanaman tebu (Saccharum officinarum Linn.). Ilmu Pertanian, 18(3), $118-126$

Basuki, B., \& Sari, V. K. 2019. Efektifitas dolomit dalam mempertahankan ph tanah inceptisol perkebunan tebu Blimbing Djatiroto. Buletin tanaman tembakau, serat \& minyak industri, 11(2), 58. https://doi.org/10.21082/btsm.v11n2.2019.58-64 
Basuki, B. 2020. Pemetaan Tipologi Lahan dan Kesesuaian Tipe Kemasakan Varietas Tanaman Tebu di Jatiroto Lumajang. Buletin Tanaman Tembakau, Serat \& Minyak Industri, 12(1),3444. http://dx.doi.org/10.21082/btsm.v12n1.2020.34-44

Djajadi, D., Hidayati, S. N., Syaputra, R., \& Supriyadi, S. 2017. Pengaruh pemupukan si c air terhadap produksi dan rendemen tebu / effect of liquid si fertilizer on yield and commercial can e content of $\begin{array}{lllll}\text { sugarcane. Jurnal penelitian tanaman industri, } & 22(4), & 176 .\end{array}$ https://doi.org/10.21082/littri.v22n4.2016.176-181

Hunsigi, G. 2001. Sugarcane in Agriculture and Industry. Kamataka Institute of Applied Agriculture Research. Sameerwadi, Bagalkot.

Ismadi, N.T. 2016. Si Hitam Manis andalan PTPN XI. Warta Puslit Sukosari PTPN XI Vol 10/09/2016

Mastur. 2016. Respon fisiologis tanaman tebu terhadap kekeringan. Buletin tanaman tembakau, serat dan minyak industri, 8(2), 98-111. Https://doi.org/10.21082/btsm.v8n2.2016.99-112

Medeiros, D. B., Silva, E. C. Da, Nogueira, R. J. M. C., Teixeira, M. M., \& Buckeridge, M. S. 2013. Physiological limitations in two sugarcane varieties under water suppression and after recovering. Theoretical and experimental plant physiology, 25(3), 213-222. https://doi.org/10.1590/s219700252013000300006

Mohseni, V. G., \& Sabbagh, S. K. 2014. Influence of adding garlic and thyme and their combination on immune response and some blood parameters in broiler. Scientia agriculturae, 2(2). https://doi.org/10.15192/pscp.sa.2014.2.2.102106

Mulyadi, M. \& Toharisman, A. 2003. Silikat: Hara Fungsional yang Berperan dalam Meningkatkan Produktivitas Tebu. Pusat Penelitian Perkebunan Gula Indonesia, pp.1-14.

Pawirosemadi. 2011. Pedoman Budidaya Tebu. Universitas Negeri Malang, Malang.

Pikukuh, P., Tyasmoro, Setyono, D. Y., \& Aini, N. 2015. Pengaruh frekuensi dan konsentrasi penyemprotan nano silika ( si ) terhadap pertumbuhan tanaman tebu (Saccharum officinarum L .). Jurnal produksi tanaman, 3(3), 249-258. https://media.neliti.com/media/publications/129544-id-none.pdf

Prasanna, S.M., \& Pattar, S. P. 2014. Research and reviews: journal of agriculture and allied sciences successful ratoon management in sugarcane . Agriculture and allied sciences, 3(4), 39-47.

Ramadhan, I.C., Taryono, \& Wulandari, R. 2014. Keragaan pertumbuhan dan rendemen lima klon tebu (Saccharum officinarum L.) di ultisol, vertisol, dan inceptisol. Vegetalika, 3(4), 77-87

Santoso, B., Mastur, Djumali, \& Nugraheni, S. D. 2015. Uji adaptasi varietas unggul tebu pada kondisi agroekologi lahan kering. Jurnal littri, 21(3), 109-116.

Sari, V.\& Haryono, K. 2020. Keragaan varietas tebu unggul baru pada fase pembibitan dengan pemberian nano silika. Agritrop 18, 195-201.

Sari, S.\& Indrawati, W. 2019. Aplikasi berbagai jenis pupuk organik terhadap karakter FMA pada rhizosfer tebu bud chip. Jurnal Penelitian Pertanian Terapan, 17(3),1-10.

Sujinah \& Jamil, A. 2016. Mekanisme respon tanaman padi terhadap cekaman kekeringan dan varietas toleran. Iptek tanaman pangan, 11(1): 1-8.

Syahri, R., Djajadi, Sumarni, T. \& Nugroho, A. 2016. Pengaruh pupuk hijau (Crotalaria juncea L.) dan konsentrasi pupuk nano silika pada pertumbuhan dan hasil tebu setelah umur 9 bulan. Jurnal produksi tanaman, 4(1), 73-81. 
Utami S.F.F., Nihayati, E., Rofiq,M., \& Djumali. 2019. Pengelompokan 6 Klon Tanaman Tebu (Saccharum officinarum L.) pada Fase Vegetatif Berdasarkan Karakter Morfologi dan Fisiologi. Jurnal Produksi Tanaman. Volume 7 (9): 1617-1625.

Yukamgo, E. \& Yuwono, N.W. 2007. Peran silika sebagai unsur bermanfaat pada tanaman tebu. Jurnal Ilmu Tanah dan Lingkungan, 2, 103-16.

Zao, D, Glaz, B \& Comntock, JC. 2013. Sugarcane leaf photoshinthesis and growth characters during development of water deficit stress, Crop Science, 80:1066-1075. 